\title{
Psychological insights on discussing societal disruption and collapse ${ }^{1}$
}

\author{
Professor Jem Bendell
}

UNIVERSITY OF CUMBRIA, UK

\begin{abstract}
As the impacts of climate change grow in number and severity, so climate distress is increasing around the world and becoming a major issue for psychologists, as both individuals and professionals. Increasing numbers of people assess that the damage that is forthcoming because of existing trajectories of atmospheric heating will lead to massive disruption and ultimate collapse of societies around the world. Some such people have been grouping together to share ideas on the implications for the rest of their lives. Many are using the concept and framework of "Deep Adaptation" to organise their sense making and actions. Their existence and ideas have led to strong criticisms from some commentators and scientists, who argue it is not correct or helpful to discuss collapse risk and readiness. This paper explores the reasons why publicly discussing anticipation of collapse has become helpful, and how criticisms of it are likely involving forms of 'experiential avoidance'. The problematic objectification of people for 'doomism' is explained, as well as the antecedents of authoritarianism that may be emerging in the criticisms of Deep Adaptation. Therefore, a case is made for how psychotherapists and psychologists can help people, including scholars, understand how their aversion to the topic of collapse - and the emotions associated with it - could be preventing dialogue and wise action at this crucial time for humanity.
\end{abstract}

\section{Whakarāpopotonga}

E rahi haere ake ana nei te tatau me te kino o te awe panoni taiao, e piki haere ana hoki te pakatokato āhuarangi huri noa i te ao, ā, me te aha e tau ana hai take matua mā ngā mātanga hinengaro i rō mahi, i waho mahi.E nui ake ana ngā tāngata e whakaaro ana ko te mutunga mai o te kino ka puta ake i nga tūmomo ara tuaora o te whakawera kōhauhau e hua ake te whakararu me te tanukunga o ngā hāpori huri noa i te ao. E whakarōpūtahi ana ètahi o ēnei tāngata ki te whakawhiti whakaaro mō ngā hua tau ki a rātau mō te toenga mai o ō rātau koiora.He maha kua huri ki te ariā me te poutarāwaho o te "Urutaunga Hōhonu" hai whakarite i ō rātau tairongo me ngā hohenga. Nā tō rātau tuaoranga, me ō rātau huatau i takia e ètahi

Bendell, J. (2021). Psychological insights on discussing societal disruption and collapse. Ata: Journal of Psychotherapy Aotearoa New Zealand, 25(1), 35-53. https://doi.org/10.9791/ajpanz.2021.05

1 An earlier version of this article was first presented as a keynote to the New Zealand Association of Psychotherapists conference, “Te Ipu Taiao - The Climate Crucible” (March 2021). 
kaikōrero wāwāhi tahā, ētahi kaimātai pūtaiao he huanga hahani e whakahau ana kāre e tika kāre rānei e whai hua te matapaki tūpono tanukunga. Ko tā tēnei pepa he tūhura i te take kua whaihua te matapakinga matawhānui whakaneinei tanukuhanga ā, te āhua nei ko te mutunga o taua matapakihanga he āhua 'karonga whakamātau'. Ka whakamāramahia ake te raru o te whakapakokonga tangata tautāwhi 'mutunga', me ngā kaiwhakamana o mua e puta haere ake ana i roto i ngā whakahahani mō te "Urutanga Hōhonu”. Nō reira, kua whakaritea heāhuatanga e taea ai te āwhina tangata, e ngā mātanga hinengaro, huitahi ki ngā ākoranga, mōhio ai me pēhea tā rātau karo i te kaupapa o te tanuku - me nga kare-ā-roto pā atu - e pākati ana pea i te whakawhitinga kōrero, mahi rangatira i tēnei wā waiwai mō te ira tangata.

Key words: climate anxiety; eco-anxiety; eco-distress; societal collapse; deep adaptation; authoritarianism; activism; doomism.

\section{Introduction}

Your anxiety or emotional distress about the situation with the climate is normal, sane, healthy and even righteous. Those difficult emotions you have been feeling may also be a painful gateway to a different expression of who you are, depending on how we support each other in that process of change. I am addressing you directly as I begin this article, to avoid any suggestion that the topic of emotional distress (whether anxiety, grief, anger, shame or depression) can be analysed as a phenomenon outside of ourselves. Rather, these emotions are being experienced by you, me and our colleagues in this field of expertise. Our emotional reactions influence the way we engage in this topic. They may influence us even more if we pretend otherwise, as some scholars may be doing in this new era of societal disruption and confusion, since the onset of widespread environmental disturbances and the COVID-19 policy context.

People who do not experience any distress, despite being exposed to the information on the situation, might be experiencing something psychopathological. Their avoidance of normal yet difficult emotions might be an instance of something termed "experiential avoidance" in psychology and which is correlated with mental health problems, such as depression, panic attacks and aggression (Chawla and Ostafin, 2007). People living that way might tell us to be more positive or to stop upsetting other people. They might begin to see us as the problem, rather than our predicament as the problem. They might tell us that we are being manipulated by bad people, so that we could consider blaming such bad people for our difficult feelings and shift some of those feelings. Some people telling us such ideas might even claim psychological expertise. However, how should we respond to such arguments if we want to be fully present to reality, take responsibility for our emotions, and communicate without fear of judgement, with the aim of making better decisions for both ourselves and other people? My belief is the most appropriate response is to look much closer at what psychology and related fields can help us understand about this difficult topic of communicating insights on how bad the situation is and will become.

Because you care about people, do not want to hurt others and even want to help them, you have probably wondered how best to communicate both your analysis and your emotions about your analysis on the situation with the environment and society. If so, then 
you are in the same situation as many thousands of scholars, educators and activists engaged in climate issues who have been wondering how best to look after our own emotional wellbeing while responsibly engaging other people on the evolving situation and our perceptions of that. In 2020, over 700 of us, from 30 different countries, signed a public Scholars Warning letter calling for more sober public engagement with the potential for societal disruption and collapse due to the direct and indirect impacts of climate and environmental change. ${ }^{2}$ The letter notes that there are many perspectives on the concept and nature of societal collapses, past, present and future. In my work I have defined it as an uneven ending of normal life, meaning the normal modes of sustenance, shelter, security, pleasure, identity and meaning. The term collapse implies that there is an ending, and then something new, rather than a breakdown and possible repair back to normal (Bendell and Read, 2021).

In this article, I will explore the question of whether such scholars are being responsible in speaking out in this way, by drawing on some relevant theories in psychology. My aim is to provide you with a stimulus for your own reflection on whether and how to discuss more publicly your own perception of collapse risk and the need for society to have more public conversations on this matter ahead of potential new policy agendas.

I share these ideas in a journal of psychotherapy because I think it important for the psychotherapy - and related - professions to engage this topic more fully and publicly to help people avoid making the situation worse as our sense of distress and vulnerability increase in the coming months and years. I am not a psychotherapist and have prioritised learning about relevant insights on psychology since 2018 as I began to witness some academics and activists suppress difficult emotions and articulate explanations of our situation and the implications in ways that reduce the humanity of certain others. I guessed that defensive, authoritarian, and xenophobic patterns would emerge counter-productively within some people in response to societal disruption and the threat of collapse, and I wanted to learn more about what could be done about that. Therefore, in this article I will clarify some of the specific dangers from such responses and the role I see for psychotherapists to engage in public life to help both scholars and the general public explore more kind and wise responses to our increasingly stressful predicament.

\section{Hypotheses on Why Discussing Collapse Risk in Public is Becoming Helpful}

After discussions with many dozens of scholars around the world over the past three years, I hypothesise that the reasons why hundreds of us are calling for more attention to societal collapse include, but are not limited to, the following seven reasons.

First, honesty. Being true with each other is an important reason for people to discuss their anticipation of collapse. Related to that is enabling more honesty in society, through the expression of what people are privately believing or considering. Research shows that not only is climate anxiety widespread but also the anticipation of collapse in our lifetimes has increased rapidly in recent years (Cassely and Fourquet, 2020).

Second, mutual self-help, to help ourselves and each other cope better with this outlook,

2 www.scholarswarning.net 
including our emotional wellbeing in the short and longer-term as we live into a destabilising future. Dialogue and community are an essential first step for that (Bendell and Carr, 2021).

Third, aggression reduction, to reduce the potential psychopathological behaviours arising from emotional suppression of this topic, which have been identified as delusion, depression and aggression by researchers of "experiential avoidance", as described earlier. These behaviours can arise from attachment to narratives of self and society, known as "worldview defence" in the "terror management" literature, due to a lack of other ways of being able to respond to feelings of confusion and vulnerability, which are associated with death aversion (Wolfe and Tubi, 2019).

People can also react to difficult emotions by reducing their appreciation of the dignity of others, thereby supporting authoritarian and violent approaches to enforce views and behaviours (which I return to below). However, the way people respond to increased awareness of their mortality is not set. For instance, there is evidence that reflection on death can lead to greater environmental commitment in the form of philanthropy (Fa and Kugihara, 2020). By discussing collapse, there can be an opportunity to transmute awareness of mortality and vulnerability into prosocial ways of thinking and acting. Deliberate processes for death reflection are well known in both spiritual traditions and philosophy, while also resulting in therapeutic benefits and pro-social implications in contemporary contexts (Arena, 2020). Inviting emotional expression and non-judgemental exploration of our situation is already proving helpful for reducing the likelihood of people responding in antisocial ways as they anticipate mortality (Bendell and Carr, 2021).

Fourth, self-transformation, for people who are ready for it, to support each other in processes of deep reflection, positive disintegration of old stories of self, and thus emergence of new ways of being (Laycraf, 2020).This can happen as we explore what really matters to us once our old stories of self, necessity and respectability are loosened by the realisation of the destructiveness and impermanence of mainstream societies. Some people are not ready for that, or they have already reached a place of self-construal where they do not prioritise this reflection anymore.

Fifth, cause identification. This reason builds upon all of the previous ones, as the work on those then allows a deeper exploration of why modern humans created this predicament. This includes looking at the ways that various forms of othering enable oppression and exploitation within and between countries (Bendell and Carr, 2021). That is more than an intellectual exercise, because it informs a sixth and seventh reason.

Sixth, path finding. This reason is to explore what to do next and why, at all scales from local to global, including how to not make matters worse, how to slow or soften societal disruptions and collapse, how to ensure that the most marginalised communities are not affected first and worst, as well as how to create more possibilities for the future (if that is what someone believes is possible). That then brings our attention to how some parts of society are already responding away from the limelight, such as the world's militaries, authoritarian elites and hedge funds, as they prepare for disruption and collapse in ways that civil society may rightly object to (Bendell, 2020).

Seventh, solidarity actions. Running in parallel to these reasons, a seventh reason to talk about collapse is to become better able to discuss effective responses to the societal disruptions and breakdowns that are occurring now, and to participate in significant 
solidarity efforts. These include humanitarian action alongside work on social and trade justice, reparations and reconciliation.

Each of these hypotheses could be further explored and added to. Given the present nature of the predicament we face, action research that focuses on trying to make a positive difference through the research itself would be a valid approach. The nature of the hypotheses touch on many different intellectual disciplines, so interdisciplinary approaches will be key. The question of whether we should discuss collapse is far more than a pure question of psychology, but insights from psychology and psychotherapy could help us to learn how and when to discuss it and with whom.

Some of the 700+ signatories to the Scholars Warning are psychologists, but most like me, are not. To help us better understand how to engage on this matter in future, the Scholars Warning initiative commissioned a review of relevant psychological research, to support current and future signatory scientists and scholars (see Kieft, in this same issue). In that literature review, the psychological research that is relevant to some of the concerns raised about the psychological implications of anticipating collapse were summarised and discussed. Rather than review the sub-field of psychology and psychotherapy on climate change, or on environmental action, the review looked across all areas of psychology to find insights on the anticipation of disruption, decline, disaster and collapse. Therefore, I believe it points towards a step change, or focus-shift, for the way people can engage in climate psychology in future. It contributes to a psychological research dimension to the new fields of both "collapsology" (Servigne and Stephens, 2020) and "Deep Adaptation" (Bendell, 2018). The former is a field of scholarship about the likelihood, nature and implications of societal collapse. The latter is "an agenda and framework for responding to the potential, probable or inevitable collapse of industrial consumer societies, due to the direct and indirect impacts of human-caused climate change and environmental degradation" (Bendell and Carr, 2021).

\section{How Anticipating and Experiencing Societal Disruption and Collapse is Affecting People}

There has been much uninformed comment in the media - and even in academic texts about the impacts of collapse anticipation on people's mental health and motivation. It is important that people considering whether and how to communicate on this topic become more aware of the range of possible sources of evidence and insight.

The centrality of behavioural psychology in previous work on climate psychology may have limited our understanding of our current predicament. The main focus has been on the individual as a consumer, and what makes them choose pro-environmental behaviours, rather than what radicalises them as citizens contributing to societal and political change, at whatever level (Adams, 2021). In the literature review by Kieft in this same issue, psychologist Jasmine Kieft discusses a few examples of where behavioural psychology has been publishing claims about negative implications of either anticipating or talking about disruption and collapse that are highly questionable, both theoretically and empirically. Such studies may suit the dominant narrative of optimism, reform and progress within its sister discipline of behavioural economics. 
Ideological assumptions of some psychology and psychotherapy researchers may have led to biased and limiting interpretations of the role of narratives of hope and agency in supporting action and avoiding mental health difficulties. For instance, hope and agency are typically understood to mean stories of reform and betterment of current socioeconomic systems, within a paradigm of material progress (as an example, see Marlon et al, 2019). That ideological limitation means that some psychologists and psychotherapists have not even considered how hope, whether a wish, expectation, intention, or deeper faith, could be expressed while also anticipating societal disruption and collapse within one's lifetime. To do that requires the courage to allow oneself to feel difficult emotions and the dissolution of some existing stories of self and society (Bendell, 2019a).

After I communicated my own anticipation of societal collapse in my "Deep Adaptation" paper (Bendell, 2018), and it was downloaded over a million times, I witnessed a wide range of responses to this topic. Sometimes scholars backtrack in public on things they have said in private. This may be for a mix of reasons, including the conservative culture of scientists, alongside not wanting to upset people or become the target of criticism (Hoggett and Randall, 2018). That is understandable, as many people experience difficult emotions when first hearing how bad our climate situation has become.

Some scientists have recently begun arguing that to suggest we will see massive disruption or even collapse in our lifetimes is demotivating and psychologically damaging (Mann, 2021). Some people who listen to such an argument might hear it as 'common sense'. However, on closer inspection, this view does not hold up so well. One study found that climate distress including "a proximal as well as a distal threat" where personal vulnerability is involved, "correlated positively with determinants of pro-environmental behaviour" (Verplanken et al, 2020). Another study in Australia found that people "feeling eco-depressed were more likely to report participating in collective climate action, while those feeling ecoanxious were less likely to join the cause" (Stanley et al, 2021). You might benefit from reading that sentence again and letting the implications settle. It suggests that being worried about climate change might not move people to activism, but feeling depressed about the situation is more likely to do so.

It is a matter of public record that the "Deep Adaptation" paper radicalised many people to then change their lives and join a new kind of climate activism, involving non-violent civil disobedience (Green, 2019; Humphrys, 2019). It is an open question whether such activism will have an effect on systems and, ultimately, either emissions cuts, drawdown or adaptation. However, it shows that the claim that apathy is the main response can be easily questioned. Further research will be necessary to determine the wider impact on apathy and agency. There is very little research on the wider forms of pro-social action that arise from people anticipating societal collapse. In one survey of members of the Deep Adaptation Forum, almost half of the respondents said they considered themselves to be taking leadership in new ways as a result of their new anticipation of collapse. Their range of actions included work on practical and emotional resilience within their communities and professions (Bendell and Cave, 2020).

One of the labels used to malign the scholars who speak out about the likelihood of societal collapse is that they are "doomers". The argument they make is that people labelled as "doomist" or "doomer" are concluding that there is no reason to explore and engage in 
pro-social and pro-environmental action due to their anticipation of further disruption and ultimate collapse of the current way of life (Mann, 2021). The evidence for such a view is typically sparse to nonexistent, even in peer reviewed studies, as I will explore further below. If "doomism" is to believe in a negative view of the future, despite the evidence, then it is doomist to believe that people will only respond to a recognition of our climate calamity and forthcoming disruption with apathy, confusion, depression, selfishness, xenophobia or bigotry. Such a view not only ignores relevant studies (Stanley et al, 2021), but also evidence from the new kind of climate activism that has arisen since 2018, where the motivation includes doing what is right because people have a heightened sense of their own mortality and that of the people they love (Extinction Rebellion, 2019). It also ignores evidence of people engaged in the Deep Adaptation Forum (Bendell and Cave, 2020).

As this is a new situation, I believe it relevant to offer some insight from my own engagement with people since 2018. In that time, I have not met many people who accept information about the possible, likely, inevitable or unfolding collapse of society and then respond with pure apathy. Rather, the fatalistic people I meet tend to be people who do not actually feel the threat to their own wellbeing or that of the people they love. I look forward to seeing some more research on this topic. However, if researchers bring assumptions that people will only act when they think they will achieve solutions to environmental problems, and ask biased questions as a result, they will miss the more fundamental existential and spiritual motivations that may be key to contemporary environmentalism. That is demonstrated by a major study of Extinction Rebellion (XR) in 2020. The researchers explained they asked "XR protesters about who, or what, is best placed to solve our environmental problems" (Saunders et al, 2020). The researchers' emphasis on "solving problems" arises from a modernist ideology, and embedding it into the survey questions meant that key aspects of the motivation and identity of Extinction Rebellion activists were excluded from the study. The framing to "solve" could be why the research found that "none of the options offered were strongly supported by XR respondents" despite the clear evidence of the high motivation of the activists. In the study there was no discussion of the power of despair or of mortality salience to the motivations of activists. Any participant observation or autoethnography, or even open-ended questions, would have helped researchers understand that the motivation of XR rebels is often quite different from past eco-activism. This reminds us that how research is as much a projection of the assumptions of the researchers as a response to what is happening in society.

It could be that negative views on how people react to anticipating collapse are based on assumptions about human nature being selfish or requiring promises of material or status gain to be motivated toward pro-social action. It is important to note that the view that human nature is basically selfish, which derives from the field of economics, has started to influence societal discussions of wellbeing. That approach also brings a utilitarian and modernist assumption of what constitutes the good society. Consequently, the field of wellbeing economics incorrectly assumes that the lesser a population experiences any negative emotions the better it is, rather than its capability for equanimity (for instance, see Piekałkiewicz, 2017). That means psychologists and psychotherapists could help by communicating alternative views more publicly more often. 


\section{Adaptation Delayism and Experiential Avoidance in Academia}

Psychotherapists and psychologists have a useful role to play in helping scholars explore how their inner worlds are affecting their contributions to the fields of climate research and policy. It should be uncontroversial to state that emotions play a key role in the shaping of scientific study, from the development of questions, means of analysis, discovering insights, and deciding what to communicate and how (Thagard, 2002). However, the idea that researchers are like machines, or aspire to be, is still widely promoted. Such a claim to objectivity is problematic for many reasons, with one reason being that it means institutions of scholarship do not help their professionals develop greater self-awareness so that greater wisdom might emerge. Without attention to how our inner worlds shape our research, analysis, and communication choices, patterns of experiential avoidance in the emotionally distressing field of climate scholarship might be distorting the quality of academic activities. Rather than allow difficult emotions of fear, sadness, shame and anger, instead the suppression of them may mean that they unconsciously drive the academic process in some scholars. That could lead to them projecting their inner worlds onto others, as well as projecting blame onto them. The existence of people who are openly sharing their views on worst case scenarios and their painful emotions about that could be regarded, consciously or (most likely) not, by some observers as threatening their own coping mechanisms as persons either experientially avoidant or at risk of depression.

Most academic research papers on climate issues claim objectivity and suggest an absence of emotional drivers for their work. That is even the case for most papers in the social sciences. A close look at one paper will reveal how this approach could be enabling experientially avoidance amongst researchers, and unhelpful aggression towards people in society being described by such research. I choose the paper "Discourses of Climate Delay" (Lamb et al, 2020) as it was widely promoted amongst both scholars and commentators and is cited as a key text for claiming there is something called "doomism" which is described as bad. It reported that "we derive our initial list of discourses from an expert elicitation of the study co-authors", which is a complicated way of saying the coauthors created their categories of discourse by conversations amongst themselves rather than analysing texts using any methods of discourse analysis. There is no evidence in this paper of any knowledge of discourse analysis methods, let alone critical discourse analysis, which would be appropriate for an attempt to explain influence of discourses on power i.e. policy agendas and decisions (Bendell et al, 2017; Gee and Handford, 2013). From a theoretical basis of using the term 'discourse' simply as a way of talking, rather than a huge field of sociological theory and research, and an empirical basis of discussing together what they want to criticise, this is what the authors wrote about what they describe as "doomism":

Doomism further argues that any actions we take are too little, too late. Catastrophic climate change is already locked-in: "The climate apocalypse is coming. To prepare for it, we need to admit that we can't prevent it" (New Yorker opinion article). Such statements evoke fear and can result in a paralysing state of shock and resignation 
(Hulme, 2019). This discourse implies that mitigation is futile and suggests that the only possible response is adaptation - or in religious versions, by trusting our fate to "God's hands". As with many other discourses of delay, the surrender category does not favour the difficult work of building climate engagement and deliberating over effective solutions. (p.4-5)

The only data they use to highlight "doomism" is one article in the New Yorker. They only reference one academic study for the claim of a "paralysing" effect (Hulme, 2019), which was not from psychology or psychotherapy, thereby ignoring a whole discipline. That academic study revealed no references in it to any of the fields that guide the analysis of discourse e.g. cognitive linguistics, narratology, discourse analysis, or critical discourse analysis. The problem with this atheoretical approach to discourse on climate is that they might inadvertently block a deeper consideration of the topics addressed. A short analysis of their statements about "doomism" in the diagram that is contained in the paper reveals the ideological assumptions that produce their claims and limit imagination.

The paper states that "doomism" implies: "Any mitigation actions we take are too little, too late." (p.2) They offer no clarification on what it is too late for. Many climate activists today, such as those in XR and Deep Adaptation, claim that it is too late for industrial consumer society, too late for reformism, too late for incremental change, and too late for imagining that people will escape further and massive loss and damage in the near future. Some people are also arguing it is too late for the ideology that underpinned the destruction and has failed to inform significant change (Bendell and Carr, 2021). Just because it is too late for certain objectives does not mean it is too late for seeking to do anything. To not look closely at this issue might suggest an unwillingness to imagine anything beyond modernity and the progress of technological consumer society.

The paper next states that "doomism" implies: "Catastrophic climate change is already locked in.” (p.2) That is a widespread view amongst many scientists and it is already happening for many people other than the authors of this paper. The paper then states that "doomism" implies: "We should adapt, or accept our fate in the hands of God or nature." (p.2) Here they imply that adaptation is inactive, and against seeking emissions reductions and drawdown, despite the evidence that people are working on this whole agenda. Accepting one's fate is assumed to be demotivating by these authors, despite there being a lot of research and current data to show the opposite - that a realisation of mortality and a relinquishment of certainty of impact or outcome can inspire courage and boldness.

By vilifying people who are seeking to integrate worst-case scenarios of climate change into their outlook and decisions, some scholars and commentators risk distracting society from a deeper focus on adaptation. That could constitute a form of 'Adaptation Delayism' that leaves the field of collapse risk, readiness and response to agencies and elites beyond the view, or potential influence, of an engaged civil society. To help address this problem, psychologists and psychotherapists could engage with scholars who are making such mistakes in their assumptions about human psychology, so that delays in engagement with adaptation are not further encouraged. 


\section{Experiential Avoidance and Authoritarianism}

A concern often expressed amongst environmental activists is that an awareness of our ecological predicament, or the negative impacts on society, will lead to various forms of fascism. That concern is not a reason for avoiding talk of collapse risk and readiness, but conversely can be a reason for engaging in it actively to try to avoid that outcome. In 2021, human rights and freedoms are already being curtailed around the world, ostensibly in response to the COVID-19 pandemic. If we care about personal dignity, liberty and accountable governance then we must address the potential for authoritarianism and associated aggressions. Psychotherapists and psychologists could play a particular role in bringing public attention to this matter, as well as exploring how to help their clients in relation to it, given that there is a low level of public awareness of how the antecedents of fascism exist in most of us and in everyday public discourse. With more awareness, people can choose to avoid contributing to the conditions for authoritarian aggression.

In this section I will summarise the psychological antecedents of fascism, before exploring the particular situation of academia, where 'experiential avoidance' could lead scholars to accidentally promoting authoritarianism.

One of the most important books on the rise of authoritarianism provides us with a salutary lesson on how society is always at risk of a descent into repressive fascism. Originally published in 1950, The Authoritarian Personality (Adorno et al, 2019) explained how authoritarianism (and repressive fascism) is not merely a political phenomenon, but the "manifestation of dispositions that lie at the very core of the modern psyche" (p12). One problem with the way "fascism" has become a label of alarm and dismissal, is that it suggests that what is being described is extreme, that there is universal agreement that it is bad, and that we are too modern and progressive for that today. Such an assumption denies how a worrying potential for supporting fascism lies in every one of us. As a new introduction to a 2019 republication of the book explained (Gordon, 2019):

Fascism is something far deeper than a political form: it correlates with psychological patterns of domination and submission that take shape in earliest childhood and later harden into a syndrome of attitudes regarding hierarchy, power, sexuality and tradition. The psyche of a fascist is authoritarian in the sense that it attaches itself to figures and strength and disdains those it deems week. It tends toward conventionalism, rigidity, and stereotypical thinking; it insists of on a stark contrast between in group and out group and it jealously patrols the boundaries between them. (p 12)

Psychological research even as far back as the mid-1930s provided insight into how some people respond to feelings of confusion and vulnerability by submitting to a powerful authority, and how they feel emotionally threatened by anyone who does not also submit to that leader, therefore gaining some sadomasochistic relief from the domination or punishment of transgressors (Fromm, 1936). If people have been taught since childhood that any difficulty is best addressed through the function of a "strict father" then they are more likely to support authoritarian approaches (Lakoff, 2006).

A focus on fascism can also lead to an ignoring of the psychological and cultural 
processes that led to authoritarian and aggressive regimes of colonisation. It is easier for many in the West to criticise 1930s Germany and Italy, than look at the attitudes and discourses that enabled Europe to maintain exploitative empires. The key psychosocial process involved in all forms of oppression is called "othering", where some people are implied to be less important than others (Bendell and Carr, 2021). That process typically involves the objectification of people. Martha Nussbaum (1995) identified seven ways in public narratives (or discourse) that people objectify others, describing them in ways that imply they have less dignity or self-worth. Such "objectification" can occur even if people think they are being concerned for the people being objectified. These methods include describing or treating someone as a tool, or lacking moral autonomy, or lacking agency, or being substitutable, or being violable, or capable of being owned, or not having a valid subjectivity. Wherever we witness people talking or writing about others in ways that objectify them in this way, then we know that oppressive power is being exerted and potential further forms of violence are being excused.

Psychotherapists and psychologists can help us to understand what is going on within us as we objectify people in such ways. For instance, it has been shown beyond doubt that the socially constructed idea of what behaviours people should be disgusted with, combined with the socially influenced habit of people not owning their emotional reactions, often leads to aggressive attitudes and behaviours against those being described as deviant (Ray and Parkhill, 2020). Research on the antecedents of fascism in the past point to the role of creating a myth of moral certainty, where values are narrowly applied and deviation is regarded as disgusting (Gregor, 2012). The psychology of disgust can combine with some people's aversion to their own difficult emotions, so that they express a "belief in silencing others" and thus authoritarianism (Tsfati, 2020, p. 488). One reason is that they feel uncomfortable about anyone whose views and life choices they regard as revealing their own submission to the narratives preferred by the current authorities in society (ibid).

This body of work offers us an analysis of what might be occurring in 2021, where a combination of factors can provide a context for the expression of authoritarian personality types. These factors include a deep incomprehension due to a decline in knowledge that capitalism is a system of choice that generates difficulties; intense confusion arising from the divergent narratives about the nature of the COVID-19 pandemic; growing feelings of vulnerability from either the disease itself or the impacts of policies on livelihoods, wellbeing and mental health; and mass media demonising people for opinions on the nature of the threat or how to respond. Already, the impact of mainstream government narratives on the threat and appropriate responses to the COVID-19 virus has been found to increase prejudices towards non-traditional or non-conservative approaches in personal lives, without any medical rationale for such a view (Golec de Zavala et al, 2020). That provides evidence for how the increased anxiety in a population, and/or government and mainstream media narratives about appropriate responses, is increasing the support for authoritarianism.

The trend towards authoritarianism is directly relevant to societal collapse because it can be regarded as both a result and dimension of such a collapse. It is also relevant to our consideration of climate change agendas, as similar processes described above are beginning to manifest in discussions about appropriate responses. The criticism of so-called "doomism" that I described above involves the objectification of people. So-called "doomers" are 
typically described as being a type of person who has been hoodwinked by bad actors, without meaningful agency or a valid subjectivity. Sometimes such criticism has even gone as far as negative comments on children activists who are described as being naïve or negative for taking more radical approaches than others (Villareal et al, 2020). In addition, in their paper criticising doomism (Lamb et al, 2020), the authors do not express how their own emotional distress might be affecting their work or that of others. They probably all have strong emotions about our environmental predicament. If some scholars are suppressing their emotional pain through believing ideas about solving a problem (climate change) then the existence of people who neither believe in that pain-alleviating idea nor in hiding their pain from public view could be upsetting to such scholars. While the scholars contributing to Lamb et al (2020) undoubtedly have emotions about the matter which influence their research, neither expressing them or exploring them reflects how experiential avoidance is regarded as an aspiration in academia rather than a pathology. Therefore, psychotherapists and psychologists could help more researchers move beyond that legacy from the natural sciences, and develop greater self-awareness.

Helping scholars to process emotions so they act less unconsciously from any repressed emotions is not only important for their self-care. It will be important to help such scholars as they engage more deeply in the question of how to respond to an anticipation of collapse. The research on the psychological antecedents of fascism shows that experiential avoidance can lead some people to express aggression in support of authoritarianism. Therefore, if experiential avoidance has influenced scholars to demonise people for their collapseanticipation, then once they admit the inevitability of societal disruption, the same experiential avoidance might shape the future narratives and proposals from such scholars,.

With that potential shift towards authoritarian views on responding to the climate emergency in mind, the arguments of one scholar on societal collapse is of particular relevance. Philosopher John Foster (2021) critiques the Deep Adaptation agenda as a "utopian aspiration" that "need never really confront the utter futility of pursuing liberty and equality and justice and material welfare and compassion and all the rest of the Enlightenment list, into the turmoil of a breaking world.” (p.1) His argument is that to focus on how we wish to live as we anticipate collapse is to foreground the needs of privileged people to maintain their worldview and entitlements, rather than explore and do what is necessary for preserving societies of life on Earth.

I share Foster's desire that people who anticipate collapse engage more courageously in public on this agenda, and that is why I have written this paper. However, I disagree with his suggestion that seeking to uphold key universal values as we try to respond usefully with our collapse anticipation is counterproductive. I know that the concepts of compassion, freedom and equality are not only modern but are found in ancient traditions. I know that arising from such values, methods of emotional processing, dialogue and decision making can lead to more wise and powerful action, rather than less. I know that nurturing such values is not a luxury, but an elementary need and dimension to human existence. Instead, there are middle class entitlements that are problematic for wise responses to the predicament. They typically include an assumption of entitlement to a better chance of life than others and a reaffirmed and superior identity and worldview to others (Bendell, 2021). If we are not aware of these entitlements in us, then we will more likely produce arguments that suggest we 
protect "us" not "them" in ways that, replicated around the world by the middle classes in hundreds of countries, will increase the fracturing of international solidarity.

It is difficult not to see any proposition that people be realistic and ditch key values as actually a call for the powerful to decide what must be done and to whom. It is also difficult not to see such an argument as reflecting an assumption of the advocate that they exist within the in-group of the agentic power wielders. Therefore, such an proposition reflects the entitlements to superiority that are likely to encourage oppression and conflict. If scholars do not realise that we are inescapably engaged in a process involving selfcomposition and identity-defence as we write about these difficult topics, then that lack of self-awareness will hamper our attempts at wisdom on the matter.

Could more psychotherapists and psychologists act as an antidote to rising aggression and authoritarianism as eco-distress grows amongst scholars and the general public? There is a need for courage, not only in holding space for individuals but also in reaching beyond the therapy context to help educate people more widely, so people can help themselves to escape becoming accidental fascists. That will be important as more influential voices call for further restrictions on liberties as a means of applying policy approaches from the pandemic to the problems of the climate crisis (Latour, 2021). While that might sound appealing to some people who experience fear and frustration in the face of environmental disruption, it could easily distract attention from deeper causes, further empower elites, and alientate public support for social transformation. It will also undermine the potential for a radical environmentalism which centres the need for personal and collective freedom from ideologies and systems which are inducing us to further compete, destroy and consume (Bendell, 2021).

Ultimately the escape from aggression may need to be found in spirituality. Some of the difficulty people have with engaging in the possibility of societal disruption and collapse is because most cultures today are death avoidant, particularly Western Eurocentric ones (Solomon et al, 2017). By that, I mean that we ignore death, rather than recognising it as a constant ongoing complement to life, where one requires the other. Such death avoidance is heightened by anxieties about death, which in turn are heightened by an absence of either an understanding or experience of ourselves as being one with a greater life force (Thich Nhat Hanh, 1987). With that greater sense of separation as an individual mortal being, we can become more attached to our culture's stories of safety, worth and legacy. That means we can hold on to those stories more tightly when sensing greater vulnerability and become more critical about anyone challenging those stories (Solomon et al, 2017). Yet, if detached from either an understanding or experience of our oneness with all life, we are less connected to sources for vitality, creativity and courage, at a time when the turbulence invites us to be radically present to what is occurring (Abhayananda, 2002).

\section{How Senior Leaders are Handicapped in Speaking About Collapse}

There may be a particular problem with the climate anxiety of senior leaders and media commentators that scholars could help with. Research on leadership has found that typical psychological traits that lead people to seek positions of power or influence relate to insecure identity structures (Harms et al, 2011). That means they may be more likely to suppress 
painful emotions associated with an awareness of vulnerability. The climate predicament presents both material risk and psychological risk, as the predicament undermines the legitimacy of societal structures that have provided the means of buttressing insecure identities. Therefore, senior leaders and media commentators may be more susceptible to experiential avoidance and the psychopathologies that result. That would be a problem at a time when we would benefit from more kind, wise and creative leadership. Therefore, there may be use in targeted engagements with senior leaders on their climate anxiety.

One challenge for senior leaders is that the discourse in our society tells us that to lead one needs to use stories of hope. Even in the psychotherapy and psychology literature, there is widespread confusion about what 'hope' means. It can mean a wish, expectation, intention or deeper faith (Bendell, 2019a). As mentioned earlier, some researchers assume hope on climate involves a belief in material progress and human control. Yet hope can be about people responding positively to difficulty, disruption and death. As experiential avoidance of emotional pain is found to be psychopathological, when hope is narrowly conceived, an emphasis on finding cause for hope could be an effort to swiftly exit difficult emotions, and thus prove to be unhelpful. Therefore, we need to be careful in our discussion and use of hope, and be alert to whether any experiential avoidance or 'worldview defence' in ourselves as researchers is influencing our analysis of this matter. One avenue for hope, which is not avoidant, could be the deeper faith that the goodness of humanity is planted deeper than any surface level conflicts, and will help us to express solidarity and reduce suffering, come what may.

Many of the typical refrains of management and leadership will not help senior leaders to respond well to the situation. Typically, they emphasise management control, and the importance of top management expressing confidence around a vision. In a situation where disruption and uncertainty become widespread, a different approach to management and leadership, which is more empathetic, dialogic, collaborative and humble, will be useful (Bendell, et al, 2017). Psychologists and others who support senior leaders, either as therapists or coaches, could help them to recognise the arbitrary nature of the standard refrains of leadership and how they could choose to move beyond them for a new era of adaptation leadership (Gosling, 2021).

With my practical and research experience as a Professor of Leadership, I am convinced that the dominant ideologies of leadership will not help people to engage well with matters of collapse risk and readiness. Therefore, leadership on adaptation to climate disruptions will need to come from all walks of life. There is a key role for people in the cultural sectors to voice what people are feeling but not speaking publicly. A good example is the US comedian Bo Burnham. His feature-length TV special "Inside" (Burnham, 2021) included a number of comedy songs which explored the theme of anticipating societal collapse or worse. Lyrics like "the quiet comprehending of the ending of it all" and "20,00o years of this, seven more to go" were powerful for reaching people who have a similar sense of foreboding to what he was singing about. His work is a digital demonstration of the creative power of the dark night of the soul and the power of retreating for contemplation. Viewing the dozens of reaction videos to "Inside" on Youtube, it is clear that such videos are a key means for people to receive ideas about society - and what to do about them. There is a need for more psychotherapists and psychologists to become active on Youtube, and react to current affairs and popular culture, to help people learn more about themselves and each other during the stressful times ahead. 


\section{Learning From Existing Practices and Research}

There are many areas of inquiry that could inform a better understanding of responses to anticipating disruption and collapse. Areas which I have no expertise on, nor have time to learn. There are many people like me, who wish to learn from psychotherapy and psychology and hope to receive usable syntheses. For instance, I have wondered, might we learn from people with degenerative disease and those who love them? Or from studies on ageing, or on being childless as adults? Might we learn from studies of people who have been through traumatic situations due to famine, conflict or violence? There must be much to learn about emotional resilience and even emotional thriving in situations that are neither stable, safe, nor improving materially.

People like me would also benefit greatly from summaries and assessments of the range of potential ways we can help ourselves and each other with our climate anxiety, or to help us become radically present to the predicament as it unfolds both locally and globally. In my own life, I have benefited greatly from discovering a number of means of support for my emotional health. For instance, participating in a regular men's group, using processes from the Mankind Project, have been useful for my ability to process difficult emotions without blaming others. Mindfulness, and the particular approach of Vipassana, or insight meditation, has also been extremely powerful in helping me to disaggregate sensations, emotions, thoughts and actions, so that I can stay engaged with difficult topics and situations without agitation directing my thoughts and actions as much as it might otherwise. The practice of breathwork, which involves a slight hyperventilation, has helped me to calm and connect with a sense of universal love. Another key practice that has changed the way I related to uncertainty and experimentation is Improvisational Theatre. It helped me to understand the habits of control and planning that were connected to assumptions of unsafety and the potential for failure and shame. In addition, a couple of experiences with Psilocybin helped me to face emotions and ideas that I did not realise I had been suppressing. That helped me to see the extent of lying that maintains our culture in a state of denial and numbness over the destruction that is occurring (Bendell, 2019b).

In particular, the practice of open-hearted dialogue that called “Deep Relating” has been useful to me. It involves people interacting where our emotional curiosity, acceptance, honesty and expression is combined with 'owning' our emotions (avoiding blame when experiencing an emotional charge or trigger), so that there can be newfound connection and trust with another on difficult topics (Bendell and Carr, 2021). It is also helpful in becoming more aware of how our own insecurities and hurts lead to us projecting negative intentions onto others, so we might lessen our judgements. It also means we can lessen our negative reactions to people when they negatively project onto us. That has been invaluable to me when becoming the object of multiple projections as people process their own thoughts and emotions about the climate tragedy. A senior member of the Deep Adaptation Forum, Katie Carr, described to me some of their work in the following way:

When people first begin to anticipate disruption and collapse they can feel overwhelming panic, powerlessness, fear, sometimes depression and anxiety. Having a sense of community, belonging, a space of unconditional positive regard in one's life, where it feels "safe enough" to share freely and openly about emotions that can 
feel unbearable when they're only existing inside us, is pretty much the most powerful source of healing that humans can provide for each other. It's our magic power. Being held and heard, non-judgmentally, is what can allow those overwhelming feelings to rise and fall, to be processed in the moment, and not stored in the body as future trauma. ${ }^{3}$

My intention in calling for more research is not to suggest that is where the ultimate truth on the human psyche is to be found, or that the best ideas on community engagement for enabling loving kindness will come from such research. There are limitations from the paradigm of mainstream psychological research for how we learn about our predicament. These limitations are due to the individualist and Western bias of much research in this discipline (Adams, 2021). That means the socially constructed notions of normality, safety, comfort, and choice, which rely on and maintain oppression of others, are not often questioned in the research. For instance, Kieft's literature review in this issue provides examples of where an uncritical questioning of societal norms has allowed theoretically and empirically weak arguments to be published and then influence subsequent condemnations of discussing collapse. Therefore, any psychotherapy and psychology research will be merely one contribution to a field of discussion and experimentation, which can also draw on and be informed by ancient spiritual traditions and other forms of knowing (Abhayananda, 2002).

I do not believe that research findings will be able to predict for certain how the general public will or will not, on average, react positively and compassionately to a growing sense of vulnerability. Rather, the extent to which more of us respond in curious, kind, and compassionate ways is up to each of us. So yes, it is time for more of us to discuss collapse, but when and how is something to keep learning about. I concur with Scholars Warning signatory Dr Susanne Moser (2020), who concludes that we must move beyond the not-toolate versus too-late dichotomy and now engage in "the political, policy, and practical work, as well as the deeper, underlying socio-cultural and psychological work, that the paradoxical tension between endings and possibilities demands”.

The climate tragedy is the most difficult situation we have had to face, so we will need to keep experimenting, and forgiving each other for mistakes of understanding and communication. That is a challenge in itself, as a mixture of personal anxieties and political tactics will increasingly pollute our dialogue with invitations to moral outrage and condemnation, rather than maintaining a sober focus on what might build towards the peaceful revolutionary change that our situation now requires. We can all benefit from learning how to more quickly notice, catch and forgive ourselves and each other for when we slip into aggressive ways of relating. Continuing to return to love, courage and inquiry will be necessary whatever the topic we are working on and however bad situations may become.

3 Personal communication, May 1 2021. I recommend the Deep Adaptation Forum as a way of finding resources, people and a community to offer that kind of support. There is also a database of practitioners who offer support: http://guidance.deepadaptation.info 


\section{JEM BENDELL}

\section{References}

Abhayananda, S. (2002). The history of mysticism: The unchanging testament. Watkins Publishing.

Adams, M. (2021). Critical psychologies and climate change. Current Opinion in Psychology, 42, 1318. https://doi.org/10.1016/j.copsyc.2021.01.007

Adorno, T., Frenkel-Brunswik, E., Levinson, D. J. \& Nevitt Sanford, R. (2019). The authoritarian personality. Verso.

Arena, A. F. A. (2020). Authenticity and the non-defensive, growth-oriented processing of death awareness [Doctoral thesis, The University of Sydney].https://ses.library.usyd.edu.au/ bitstream/handle/2123/23403/Arena_AFA_thesis.pdf

Bendell, J., Sutherland, N., \& Little, R. (2017). Beyond unsustainable leadership: Critical social theory for sustainable leadership. Sustainability Accounting, Management and Policy Journal, 8(4), 418-444. https://doi.org/10.1108/SAMPJ-o8-2016-0048

Bendell, J. (2018). Deep adaptation: a map for navigating climate tragedy. Institute for Leadership and Sustainability (IFLAS) Occasional Papers Volume 2. University of Cumbria. (Unpublished.) http://insight.cumbria.ac.uk/id/eprint/4166/

Bendell, J. (2019a, October 19). Hope in a time of climate chaos. UK Council for Psychotherapy Conference, London, UK. http://insight.cumbria.ac.uk/id/eprint/5463/

Bendell, J. (2019b). Extinction Redemption, in Letters to the Earth: Writing to a planet in crisis (pp. 46-49). William Collins.

Bendell, J. (2020, November 11). If guys with guns are talking about collapse, why can't we? JemBendell.com. https://jembendell.com/2020/11/11/if-guys-with-guns-are-talking-aboutcollapse-why-cant-we/

Bendell, J. \& Cave, D. (2020, June 8). Does anticipating societal collapse motivate pro-social behaviours? Institute for Leadership and Sustainability. http://iflas.blogspot.com/2020/o6/doesanticipating-societal-collapse.html

Bendell, J. (2021) Deeper implications of societal collapse: co-liberation from the ideology of e-s-c-a-p-e, in Bendell, J. \& Read, R. (Eds) Deep adaptation: Navigating the realities of climate chaos. pp109-137. Polity Books.

Bendell, J. \& Carr, K. (2021). Group facilitation on societal disruption and collapse: Insights from Deep Adaptation. Sustainability 2021, 13, 6280. https://doi.org/10.3390/su1311628o

Bendell, J. \& Read, R. (Eds) Deep adaptation: Navigating the realities of climate chaos. Polity Books.

Burnham, B. (2021) Bo Burnham: Inside, Netflix, May zoth.

Cassely, J-L. \& Fourquet, J. (2020). La France: Patrie de la collapsologie? Fondation Jean Jaures () IFOP. https://jean-jaures.org/nos-productions/la-france-patrie-de-la-collapsologie

Chawla, C. \& Ostafin, B. (2007). Experiential avoidance as a functional dimensional approach to psychopathology: An empirical review. Journal of Clinical Pyschology, 63(9), 871-890.

Extinction Rebellion. (2019) This is not a drill. Penguin.

Fa, H. \& Kugihara, N. (2020). Does concern about death help to increase donations for environmental charities? Examining the impact of mortality salience on pro-environmental behaviors in East Asia. The International Journal of Organizational Innovation, 13(2) 175-199.

Foster, J. (2021, July 5). Facing up - facing out or facing in? Global Discourse Blog. https:// globaldiscourseblog.co.uk/2021/07/05/facing-up-facing-out-or-facing-in/

Fromm, E. (1936). Sociopsychological Dimensions, in J, Horkheimer (Ed.), (1936) Studies in Authority and the Family. https://opus4.kobv.de/opus4-Fromm/files/35403/1936a-o16-eng.pdf 
Originally in German. “Sozialpsychologischer Teil”, Studien über Autorität und Familie Forschungsberichte aus dem Institut für Sozialforschung, Max Horkheimer et al., Lüneburg, Dietrich zu Kampen Verlag, 1987 (1936), pp. 77-135.

Gee, J.P. \& Handford, M. (2013). The Routledge Handbook of Discourse Analysis (1st ed.). Routledge. Golec de Zavala, A., Bierwiaczonek, K., Baran, T., Keenan, O., \& Hase, A. (2020). The COVID-19 pandemic, authoritarianism, and rejection of sexual dissenters in Poland. Psychology of Sexual Orientation and Gender Diversity. Advance online publication. https://doi.org/10.1037/ sgdoooo446

Gordon, P. E. (2019). Introduction, in T., Adorno, E., Frenkel-Brunswik, D. J. Levinson, \& R. Nevitt Sanford (Eds.) The authoritarian personality. Verso. xxiii-xl.

Gosling, J. (2021). Leadership and management in a context of deep adaptation, in Bendell, J. \& Read, R. (Eds) Deep adaptation: Navigating the realities of climate chaos. Polity Books 187-198.

Green, M. (2019, April 11). Extinction Rebellion: Inside the new climate resistance. Financial Times. https://www.ft.com/content/9bcb1bf8-5b20-11e9-9dde-7aedcaoao81a

Gregor, A. (2012). Fascism: The antecedents, in totalitarianism and political religion. Stanford University Press. https://doi.org/10.1515/9780804783682-007

Harms, P. D., Spain, S. M., \& Hannah, S. T. (2011). Leader development and the dark side of personality. Leadership Quarterly, 22, 495-509.

Hoggett, P. \& Randall, R. (2018). Engaging with climate change: Comparing the cultures of science and activism. Environmental Values, 27(3), 223-243(21).

Hulme, M. (2019). Is it too late (to stop dangerous climate change)? An editorial. Wiley Interdisciplinary Reviews - Climate Change, 11(1), e619.

Humphrys, J. (2019, April 17). Extinction Rebellion: Noble and necessary or a pointless nuisance? YouGov. https://yougov.co.uk/topics/science/articles-reports/2019/04/17/john-humphrysextinction-rebellion-noble-and-neces

Lamb, W., Mattioli, G., Levi, S., Roberts, J., Capstick, S., Creutzig, F., Minx, J., Müller-Hansen, F., Culhane, T. and J.K. Steinberger, J. (2020). Discourses of climate delay. Global Sustainability, 3, E17.https://doi.org/10.1017/sus.2020.13

Lakoff, G. (2006). Thinking points: Communicating our American values and vision. Farrar, Strauss, and Giroux.

Latour, B. (2021) After Lockdown: a Metamorphosis, Translated by Julie Rose, Polity.

Laycraf, K. C. (2020). The theory of positive disintegration as future-oriented. Annals of Cognitive Science, 4(1), 118-126.

Mann, M. (2021). The new climate war: The fight to take back our planet. Public Affairs Books.

Marlon, J. R., Bloodhart, B., Ballew, M., Rolfe-Redding, J., Roser-Renouf C., Leiserowitz A., Maibach E. (2019). How hope and doubt affect climate change mobilization. Frontiers in Communication, 4.

Moser, S. M. (2020). The work after "It's too late" (to prevent dangerous climate change). WIRE Climate Change, 11(1).

Nussbaum, M. (1995). Objectification. Philosophy and Public Affairs, 24, 249-91.

Piekałkiewicz, M. (2017). Why do economists study happiness? The Economics and Labour Relations Review, 28, 361-377.

Ray, T. N., \& Parkhill, M. R. (2020). Examining disgust and emotion regulation difficulties as components of aggression toward perceived gay men. Psychology of Violence, 10(4), 462-471. https://doi.org/10.1037/vioooo0265 


\section{JEM BENDELL}

Saunders, C., Doherty, B. \& Hayes, G. (2020). A new climate movement? Extinction Rebellion's activists in profile (CUSP Working Paper No. 25). Centre for the Understanding of Sustainable Prosperity. https://cusp.ac.uk/themes/p/xr-study/

Servigne, P. \& Stephens, R. (2020). Another end of the world is possible. Polity Books.

Solomon, S., Testoni, I., \& Bianco, S. (2017) Clash of civilizations? Terror management theory and the role of the ontological representations of death in contemporary global crisis. Applied Psychology, 24(3), 379-398.

Stanley, S.K., Hogg, T.L., Leviston, Z., Walker, I. (2021). From anger to action: Differential impacts of eco-anxiety, eco-depression, and eco-anger on climate action and wellbeing. The Journal of Climate Change and Health, 1, https://doi.org/10.1016/j.joclim.2021.100003

Thagard, P. (2002). “The passionate scientist: emotion in scientific cognition" in P.

Carruthers, P., Stich, S., and M. Siegal (Eds.), The cognitive basis of science. Cambridge University Press. pp 235-250.

Thich Nhat Hanh. (1987). Interbeing. Parallax Press.

Tsfati, Y. (2020). Personality factors differentiating selective approach, selective avoidance, and the belief in the importance of silencing others: Further evidence for discriminant validity. International Journal of Public Opinion Research, 3(3), 488-509. https://doi.org/10.1093/ijpor/ edzo31

Verplanken, B., Marks, E., Dobromir, A.I. (2020). On the nature of eco-anxiety: How constructive or unconstructive is habitual worry about global warming? Journal of Environmental Psychology, 72, https://doi.org/10.1016/j.jenvp.2020.101528

Wolfe, E \& Tubi, A. (2019). Terror management theory and mortality awareness: A missing link in climate response studies? Wire Climate Change, 10(2).

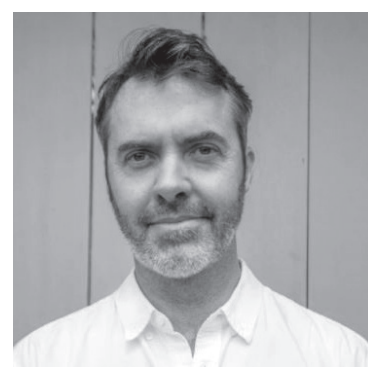

Jem Bendell is a Professor of Sustainability Leadership with the University of Cumbria, founder of the Deep Adaptation Forum, and strategist for Scholars Warning. He works as a researcher, educator, and advisor on social and organisational change, with over 25 years' experience in sustainable development initiatives in over 20 countries. In 2018, he authored the viral "Deep Adaptation" paper, downloaded around a million times. Since then he works on helping people to understand and collaborate on how to reduce harm, save more of the natural world, and find meaning from the catastrophic impacts of the global ecological and climate disaster. www.jembendell.com 